\title{
The Public and Private Spheres, Sociopolitical Integration and the Demands of Difference: the Responses of Multiculturalism*
}

\author{
Bruno Sciberras Carvallho \\ Universidade Federal do Rio de Janeiro, Brazil
}

The article seeks to discuss strengths and problems of the assumptions of difference and of the ideals of sociopolitical integration in multiculturalist perspectives. The analysis is divided into three parts. In the first I look to show that the incorporation of two themes central to communitarianism - its questioning of the procedural demarcation of the boundaries between private and public spaces, and its critique of the theory of the subject that sustains liberal theses - has been essential to how the public is conceptualized in multicultural approaches, although, as I shall show, the two theoretical lineages diverge in important aspects. In the second part, I analyze different conceptions of the public developed by multiculturalist authors, seeking to demonstrate that their perspectives present tensions, generally linked to an uncertain articulation between the premises of difference and the possibilities for social and political integration. Finally, though emphasizing the originality of their critique of fixed political conceptions of public and private, I argue that some important limiting factors exist in multiculturalist theories.

Keywords: Political theory; multiculturalism; minorities; identities; difference. 
$\mathbf{M}$ any political theories make use of the distinction between public and private to delineate boundaries between the domain of politics and what should be confined to a personal dimension. The oikos and polis distinction that arose in Ancient Greece, for example, foregrounded the singularity of the latter in its demarcation of a political instance where men occupying equal positions could deal with questions of the State through the application of reason ${ }^{1}$. Over the course of the development and institutionalization of liberalism, an inflection took shape in which the private dimension, sometimes including even civil society, becoming more highly valued than public spheres. Yet even in contemporary political theories, these concepts lack any clear or univocal acceptation. The ideal of the public sphere and its grounding in the notion of civil society by itself already implies tensions, presupposing as it does the coexistence of private interests and social or shared conceptions (see SELIGMAN, 1998). Moreover it should be observed that civil society can refer to both a dimension constitutive of modern public space and a domain exclusively linked to the market economy and interpersonal exchanges.

The sheer diversity of perspectives reveals the difficulties faced in responding to various issues that become even more complex in the face of new conflicts and cultural demands, especially those based on notions of difference ${ }^{2}$. Authors linked to multiculturalist approaches have contested the meaning of conceptualizing the 'public' and its political effects through egalitarian and universal ideals that presuppose a standardized system of rights. They also question the notion of a public space composed of impartial subjects who present themselves in a form distinct from their private subjectivity. What seems to be at stake, in turn, is the need to reflect on the incoherences of the idealization of a public sphere that can generate consensus and overcome differences, with the latter becoming restricted to 'tolerated' private spheres. Multiculturalist authors argue that this overcoming of differences and interests is not without problems and is subject to two important critiques. First, inequalities and forms of power are reproduced in public spaces that render the ideas of consent and free

\footnotetext{
${ }^{1}$ For an introductory analysis of various directions that the public-private distinction can take, see Weintraub (1997).

${ }^{2}$ Following multicultural approaches, here I assume a direct relation between the public sphere and political institutions. According to the theories examined later in the article, public debate, though independent, only makes sense when directly articulated with conceptions of justice and rights formalized at political-state level.
}

(2016) $10(3) \quad$ - $0002-2 / 25$


debate problematic. Second it is impossible for agents to abandon their own values and interests for the benefit of an impartial collective good. In contrast to a homogenizing meaning, multiculturalist perspectives assume the primordial political task to be one of recognizing differences in both the private and public sphere.

Taking into account the emphasis on the importance of difference in contemporary political debates, the primary aim of the present article will be to analyze the coherence of the theories of three authors linked to multiculturalist lineages - Will Kymlicka, Iris Young, and Bhikhu Parekh - and their respective normative conceptions of the public and private spheres $^{3}$. Despite the divergences evident in their understandings, all three theorists question the possibility of overcoming differences and the belief in the neutrality of public space, ideally reflected in the organization of formal political institutions. Such neutrality appears unattainable given that social conditions always end up making themselves present in the processes of public communication. Furthermore, this understanding and its assumption of a correct and rational form of public debate, reifies dichotomies like public-private, reason-emotion or universal-particular, which tend to conceal the fact that the outcomes of such interactions reflect the interests of particular groups and classes. One of the most perverse effects of these dichotomies is to confine to the 'private' - and thus to the supposedly non-publicizable or politicizable - realm questions that are essential to understanding diverse sectors and groups of society. As Young (2011, p. 164) suggests, an egalitarian policy based on the notion of assimilation means 'including' groups in the process after the latter has already started - that is, after the rules and patterns, allegedly blind to differences, have been established to the benefit of some groups.

In this article, I discuss some of the strengths and weaknesses of the theoretical premises employed by Kymlicka, Young, and Parekh. One of the key questions concerns the limits of multiculturalist policies in relation to processes of intergroup and intragroup articulation. In particular, we need to ask what precise meaning of 'public' is supposed and advocated by the authors concerned. In relation to the field of

3 These three particular authors were chosen due to the wide dissemination of their books and articles, usually the most cited sources in studies on multiculturalist issues. Though aware of the differences in their theories, I emphasize the similarities in order to examine some of their shared strengths and weaknesses of their ideas concerning the public and private domains. Specific differences in their theories will be examined in the final section of this article where I also question the coherence of conceiving them as homogenous part of the same theoretical current. 
contemporary political theory - notwithstanding other approaches, especially feminism, which have also extensively analyzed notions of the public and private - the contribution developed here is targeted specifically at the problematization of normative meanings of multiculturalism, which very often reveal tensions in relation to their observations of claims of difference.

In order to develop these questions, I begin by discussing the critique of the concept of neutrality elaborated in their theories. In this introductory section, I look to show that the incorporation of two themes central to communitarianism - its questioning of the procedural demarcation of the boundaries between private and public spaces, and its critique of the theory of the subject that sustains liberal theses has been essential to how the public is conceptualized in multicultural approaches, although, as I shall show, the two theoretical lineages diverge in important aspects. Next, I analyze the different conceptions of the public developed by multiculturalist authors, seeking to demonstrate that their perspectives present tensions, generally linked to an uncertain articulation between the premises of difference and the possibilities for social and political integration. Finally, in the conclusion I examine the general strengths and problems of the theories of the selected authors. Though emphasizing the originality of their critique of fixed political conceptions of public and private, I argue that some important limiting factors exist to their theories. These problems primarily stem from two sources. The first relates to the absence of any adequate analysis of the limits to the concession of special rights to particular groups due to the existence of cultural aspects that may curb the freedom and autonomy of agents. Second, I note the problems involved in the supposition of a sovereign subject who is always capable of questioning and abandoning social and cultural affiliations.

\section{Neutrality and the problems with the ideal of universality}

For authors associated with the multiculturalist approach, the central problem with the public-private distinction is the premise of neutrality where the public domain is constituted by agents without their concrete specificities. In parallel, this idea implies that political institutions should be disconnected from the identities of their citizens, indifferent to whether social groups have the capacity to reproduce their values and practices. Cultural aspects are thus understood as part of the private sphere to be tolerated, free from the interference of any public and political body. 
In contemporary political theory, Rawls $(1971,2000)$ seems to be the most important reference point for this view, representing a kind of theorization in which public space demands not only the exclusion of the differences and biases of the participants but also the predetermined control of what can be effectively debated. Hence, justice takes precedence over individual conceptions of the good. Rawls's (2000, pp. 72-76) formulation of the difference between the notion of a 'political person' that grounds the debates on justice as equity and a 'noninstitutional identity', with its diversity of values and associations, encapsulates this conception of how the public domain is structured. Other important references, also critiqued by multiculturalist theories, are approaches associated with Habermas (1997), which suggest that public debate, even in highly plural social contexts, can enable generalizing and impartial forms of understanding. According to Habermas (1997, pp. 38-39), this possibility is manifested above all in modern and post-conventional societies that stimulate the reflexivity of their cultural traditions.

Some of the multiculturalist arguments against the theorization of impartiality and neutrality stem from the liberalism versus communitarianism debate that unfolded over the last quarter of the twentieth century (KYMLICKA, 2010, pp. 18-19). Among other authors ${ }^{4}$, Charles Taylor (2000) and Michael Sandel (1982) formulated theories that questioned the idea of neutrality underlying the liberal differentiation between the public and private. Contesting the liberal separation between law and conceptions of the good, they argue that the latter cannot be constituted autonomously but only through the ways of life and practices of the societies and communities to which individuals belong. As a corollary, defending the sociocultural characteristics of these communities is justifiable insofar as these cannot be adequately protected by individual rights.

Respecting the limits set for the present article, it is worth noting briefly how authors labelled communitarianist object to positions of neutrality in public and political spaces and the limiting of differences to the private sphere. Recognizing the social embedding of agents, Taylor (2000, p. 201) criticizes procedural approaches that take society to be an association of individuals particularized by their conceptions of the good. The most problematic effect of this atomistic ontology, the author argues, is that

\footnotetext{
${ }^{4}$ Due to the objectives and constraints explicated above, the analyses undertaken in this section are limited to critical questions specifically posed by Charles Taylor (2000) and Michael Sandel (1982), without the inclusion of other important works in the communitarianist debate. For a general introduction to communitarianism, see Bell (2004, pp. 01-20).
} 
any socially or politically defined notion of the good life is rendered illegitimate, meaning that the boundaries of private and public spaces are demarcated in such a way that little space is left for reflection on the sharing of social values.

Taylor (2000) makes three major criticisms of this set of ideas. First, they are basically inviable and ethnocentric given that few societies can survive without socially endorsed conceptions of the good (TAYLOR, 2000, p. 203, p. 266). Second, these ideas fail to capture the dialogical and mediated nature of identities and the sheer diversity of notions of the good life, valorized precisely because they are produced through common actions and histories. The effect of these dialogical dimensions on public spaces is the valorization of bonds of solidarity and patriotism that engender 'us-identities' (TAYLOR, 2000, pp. 207-213). Finally, Taylor (2000, p. 269) notes that the premise of neutrality implies the non-recognition of minorities and a hegemonic culture that inculcates images of inferiority in relation to some groups.

Another idea to have produced waves in the multiculturalist approach is the critique advanced by Sandel (1982) of the thesis of the precedence of legal conceptions over ideas of the good in 'deontological liberalism'. Particular emphasis is given to Sandel's interrogation (1982) of the foundational aspects of a political configuration shaped by the principles of independence or neutrality. In this view, "only when I am governed by principles that do not presuppose any particular ends am I free to pursue my own ends consistent with a similar freedom to all" (SANDEL, 1982, p. 06). The author critiques this conception, rooted in Kant, of a subject endowed with an autonomous and rational will, free of sensory and social biases. The requirement to situate oneself outside empirical contingencies sets the grounds for both moral law and public debate. It is the principle of unity - in response to the disorderly flow of representations and constraints of practical experience - that founds the idea of the precedence of justice present in the theories of Rawls and Dworkin, for example.

Sandel (1982, p. 31) argues that the precedence attributed to justice should be taken as conditional, relevant in societies with a high degree of individuality and conflict, rather than absolute. At the same time, Sandel (1982) draws attention to a vast range of social institutions linked to notions of fraternity and benevolence where justice, though operative, is not a fundamental and indispensable instance. As examples he cites a wide range of ethnic, religious, cultural and linguistic communities, resident associations, student and worker groups, unions and other associations that express clearly defined 
common identities and purposes. In these cases, justice, rather than being conducive to moral improvement or virtue, can become transformed into a vice since its premises of universality are linked to a specific type of subject and set of social relations, informed by conflicts over scarce goods and by multiple desires and interests (SANDEL, 1982, p. 34).

Incorporating various aspects of these critiques, multiculturalist theories argue against the liberal view that cultural belonging or inequalities linked to identities can be adequately dealt with through universal and egalitarian rights. The basic point questioned is the idea that cultural associations and distinctions should be limited to the private field without reaching public and political spaces. Attention is focused especially on the fact that indispensable government decisions on issues like languages, education and symbols, for instance, necessarily recognize and reproduce particular aspects of ethnic or national groups, valorizing some moral outlooks at the cost of others. Hence, contrary to what universalist liberal approaches imagine, there exists an egalitarian basis to assuring distinct rights for specific groups or some degree of autonomy for national minorities.

Arguing along similar lines to Taylor (2000), Parekh (2000, p. 199-202) contests traditional models of political integration that fail to take into account the plurality of minorities found in public space and their diverse demands. A core problem with the procedural model is its presupposition that a political system may be taken as legitimate simply by ensuring stability, thus allowing this model to by-pass the moral debate on various substantive issues, which are relegated instead to be private. Parekh (2000) describes the idea of a morally neutral and culturally non-coercive politics impermeable to agendas marked by different conceptions of good life - as an illusion.

Kymlicka (1995, pp. 159-163), for his part, criticizes theories of the subject that presuppose a differentiation between the public agent and the individual embedded in everyday relations. What seems incoherent, in this case, is the thesis that agents have autonomy in public space while behaving differently in private spheres. Kymlicka (1995, p. 162) argues that John Rawls fails to account for why individuals who believe their personal aims are unquestionable would accept a public sphere based on neutrality and on overlapping points of consensus. In his words, "Rawls has not explained why people who are communitarians in private life should be liberals in political life" (KYMLICKA, 1995, p. 162). 
Young (2011, pp. 100-101) also analyzes the contradictions of the notion of an impartial subject, emphasizing that the treatment of all questions via the same universal moral rules eliminates diversity and reduces plurality to one single meaning of subjectivity. The result is a kind of totalizing morality that, based on a notion of universal reason, engenders a dichotomy between impartiality and particularisms that lead to the reproduction of specific patterns of domination. Far from being an impartial or neutral fact, this political philosophy ends up reproducing an ideal of male, white, bourgeois citizenship, defined by discourses taken to be appropriate, controlled and non-emotional forms of conduct, as well as racial categorizations and exclusions based on economic class. As well as the problems associated with generating barriers and excluding minority groups, the most negative consequence of these ideological aspects, linked to notions of wider interest and justice, is the absence of public debate, given that the rational and universal criteria are constructed in opposition to the particularities of the dominated groups.

It is important to note, however, that although authors linked to multiculturalism share critiques of standard predetermined notions of public and private, as well as being in agreement concerning the social construction of individual identities and choices, some factors exist that distance them from communitarianist approaches. Taylor (2000, p. 299) himself, despite arguing for a politics of difference in specific cases, also emphasizes the danger of fragmentation caused by a lack of solidarity, sympathy or interaction between local groups, religious followers and ethnic minorities. In his view, the absence of agreements and pacts turns relations into conduits of legal disputes with society organizing the public debate solely in defence of selective rights that entrench antagonisms between parties (TAYLOR, 2000, pp. 300303).

Young (2011, pp. 226-229) counterposes her model of urbanity - with nonexcluding democratic social relations that allow all groups a voice - to the ideal of community that in her view implies a logic of identity. The problem with communitarianism is, she argues, its tendency to merge subjects as part of a vague ideology of shared values and practices. Hence Young (2011) suggests that communitarianism ends up negating difference and assuming a desire to turn social diversity into a homogenous and transparent unity, a project that would deny the basic asymmetry of subjects. 
Taking a different line, Kymlicka (2010, p. 20) argues that minorities or ethnic groups do not usually question the parameters of liberal democracy, seeking instead conditions of equality and a new model of citizenship that allows cultural accommodation. His proposal, distinct from communitarianism, is to combine the reflection on minority rights with the development of freedom and self-determination, including as part of a questioning of behaviours internalized by socialization processes (KYMLICKA, 2004, p. 209). Hence, attention must be paid to the dangers posed to autonomy when particular collective notions of the good become institutionalized (KYMLICKA, 1995, p. 163; PAREKH, 2000, p. 206). Kymlicka (1995, pp. 35-44; 2010, pp. 21-23) therefore distinguishes between legitimate demands for 'external protection', which seek greater equality in the relations between groups and the defence of particular minority practices, and demands for 'internal restrictions', which, seeking to dispel dissensions within groups, curb individual rights.

A number of questions thus distance multiculturalism from communitarianist proposals. First, the social inclusion of individuals, though considered by both approaches, is viewed somewhat differently: while communitarianism takes social values and practices to be definitive of the individual, multiculturalist authors presume that agents are able to critically evaluate and detach themselves from these social dimensions. Furthermore, we should distinguish the normative communitarianist proposal of encouraging communal values from the multiculturalist emphasis on the valorization of differences and autonomy.

\section{Diversity with integration: tensions in multiculturalist notions of the 'public'}

Despite the importance of communitarianist critiques of liberal political configurations and premises, the specificities of multiculturalist arguments are clearly revealed in their conceptions of public space and how political forms respectful of differences can be constructed. Over the course of developing their works, these authors have sought to respond to repeated criticisms of the potentially disaggregating and essentializing nature of the multiculturalist stress on the identity differences existing between social groups. The responses of Kymlicka, Young, and Parekh to these critiques have generally centred on defending formulations of a public space in which integration and accommodation comprise fundamental categories. However, though given a variety 
of meanings by these authors, the alliance between difference and integration does not appear devoid of problems, as I shall try to show below.

The divide formulated by Kymlicka (1995) between the public and private spheres can be more clearly understood through his notion of 'societal culture' (KYMLICKA, 1995, pp. 76-80). This concept refers to the values and memories shared by social actors, as well as the common institutions and practices that found public spaces. However, not every culture is compatible with societal cultures since the latter are products of modernity, involving large social configurations supported by state apparatuses. Although they involve common languages and institutions, societal cultures do not manifest homogenous customs and values. Rather, they reflect the pluralism inherent to modern societies (KYMLICKA, 2010, p. 25) ${ }^{5}$. The core aspect to highlight here is that, Kymlicka argues (2010), societal cultures have not come under question in the claims for multiculturalist rights. In other words, the demands made by minorities, especially immigrants, do not include the creation of new and distinct societal cultures, but emphasize instead the right to maintain their specificities in a private dimension, embedded in societies respectful of the diversity of values and lifestyles. The demand to create societies is reflected only among what the author defines as 'national minorities', populations incorporated through the processes of colonization or conquest.

Hence, the private sphere is essential to the sociopolitical structure projected by Kymlicka. Societal culture should be understood primarily as a field of individual choices and should adapt to diversity as a way of fomenting the autonomy of social actors. The aim in granting 'polyethnic rights' is not to develop groups but to develop individuals, enabling them, once fully adapted to the hegemonic societal culture, to make better life choices, including questioning the values and traditions of their cultures of origin. Here Kymlicka (1995, p. 81) once again presumes the possibility of the individual defining his or her inner life in accordance with the values deemed the most important. In the case of national minorities, the provision of forms of self-government also enhances the

\footnotetext{
${ }^{5}$ Seeking to clarify his argument, Kymlicka (2010, p. 25) differentiates between culture in the 'ethnographic' or 'thick' sense and culture in a 'thin' sense. Taking into account this differentiation, it is worth observing that citizens of a modern liberal State do not tend, for example, to share the same habits, customs or religions, though they are associated with a culture (in the thin sense) that manifests specific institutions and idioms.
} 
conditions for autonomy insofar as it reduces inequalities between members of different communities.

In this way, Kymlicka (1995, pp. 152-155) seeks to respond to a frequent criticism directed at multiculturalism, namely that policies targeted at cultural minorities potentially restrict individual basic rights, given the existence of oppressive cultures and traditions. This highlights the potential conflicts between the valorization of tolerance and the valorization of autonomy, a complex problem given the existence of groups and cultures that do not taken individual autonomy to be an unquestionable ideal. At various moments the author emphasizes the importance of separating 'external protections' from 'internal restrictions' and rejecting the latter: "promoting individual freedom or personal autonomy seems to entail intolerance towards illiberal groups" (KYMLICKA, 1995, p. 154). Although public space should allow means of instituting more egalitarian relations between minorities and majority groups, cultural forms that curb autonomy should be inadmissible, suggesting the need to think of non-coercive modes of intervention via negotiations, incentives and agreements.

Kymlicka (1995) also looks to respond to the idea that multiculturalist policies entail the risk of disuniting or even dissolving societies. In his view, such policies are positive since they sustain public debates based on common concerns and solidarity (KYMLICKA, 1995, pp. 173-174). The author argues that the accommodation of cultural differences via 'differentiated citizenship' is essentially designed to promote inclusion, including the voices of minorities in debates and social institutions. Citing research that showed a strong affiliation of immigrants with their new countries, especially in the second or third generations, the author emphasizes that there is no empirical evidence to suggest that multiculturalist policies pose threats to stability (KYMLICKA, 1995, pp. 178). Potential integration problems arise solely from policies aimed at national minorities who are seeking some form of independence. In these cases, where minorities take themselves to be distinct nations or peoples, the public debate is made unstable by the past conquest of territories or broken agreements, generating distinct political communities (KYMLICKA, 1995, p. 182). The concession of some degree of selfgovernment, nonetheless, would be the best way to deal with the problem, he argues, avoiding the risk of any rejection of demands leading to renewed conflicts or separatist nationalisms. 
However, one weakness in Kymlicka's argument (2010) is the attempt to defend both the particularities of social groups and the broader societal culture, or what he in later texts prefers to call "processes of nation-building" (KYMLICKA, 2010, pp. 203-298). This becomes explicit when he approximates his approach to Dworkin's (1985), calling attention to the need to value the major cultural configurations and institutions to which individuals are submitted (KYMLICKA, 1995, pp. 82-83). Hence, every agent should be connected to an institutionalized culture, a space that lends support to his or her choices and autonomy, thus allowing the "freedom to move around within one's societal culture, to distance oneself from particular cultural roles, to choose which features of the culture are most worth developing, and which are without value" (KYMLICKA, 1995, pp. 90-91). In cases, though, where immigrants, for example, try to redefine national borders and establish some kind of self-government, Kymlicka (1995) argues that denying such privileges is legitimate, given that immigrants, when they move, necessarily cut some of the ties with their countries of origin and should therefore aim to integrate into the new societal culture of which they have become part (KYMLICKA, 1995, pp. 95-96). A normative premise exists that integration will eventually occur in polyethnic contexts, meaning that multiculturalist policies, when they seek to counter the disadvantages faced by minority groups and the non-recognition of their practices, are primarily intended to enable a transitory adaptation (KYMLICKA, 2010, pp. 27-31; 1995, pp. 173181). Thus "integration is a two-way process - it requires the mainstream society to adapt itself to immigrants, just as immigrants must adapt to the mainstream" (PAREKH (2000), cited in KYMLICKA, 1995, p. 96).

But here various questions surface: why should the normative political direction be linked to the adaptation and development of individual capacities to choose? What specific requirements would indicate acceptable and legitimate forms of integration for this theoretical approach? Moreover, why would refusing to integrate be an illegitimate way of reappraising belonging? Why could it not be seen as an 'external protection' or as an expression of the autonomy of the subjects? Kymlicka's theory seems to contain the questionable assumption that societal cultures, with their historical development of multicultural agreements and interactions, cease to face any real problems, unlike minorities cultures and groups that may sometimes disrespect individual autonomy and freedoms. Additionally, insofar as the author presumes types of demands and public debate focused necessarily on integration and adaptation, his theory tends to weaken 
multiculturalism's own critique of the idea of universality that informs most liberal political configurations. In elaborating his normative project of valorizing autonomy and reworking the liberal project in multicultural contexts, Kymlicka ends up reproducing rigid notions of the public and private spheres, especially the belief that personal insertion in a culture provides the possibility for identifying experiences and conceptions of the good as either valid or invalid (KYMLICKA, 1995, p. 83). As well as failing to define the relations between individuals and their culture sociologically, informed instead by the questionable premise that the agent can evaluate his or her social insertion autonomously, this formula also suggests a normative direction that tends to exclude from public space those cultures based on traditional and non-liberal models of social relationship.

The concept of the public sphere formulated by Iris Young (2011) is somewhat different, theorized on deliberative bases, especially in her later works. Although she presents similar normative premises, she highlights a question left undeveloped by Kymlicka, exploring the relational and non-essentialist aspect of identities, which has important consequences for the political domain. According to Young (2000, pp. 102107), every social or cultural group possesses a diversity that prevents it from being viewed homogeneously since individuals do not share the same characteristics and indeed sometimes even reject the identities attributed to them. But the essential question defining this internal diversity is the belonging of agents to multiple groups. The heterogeneity of subjects is taken as inevitable and an aspect to be recognized politically, challenging ideals that imagine a pure and unified identity (YOUNG, 2011, p. 153).

Differences do not emerge from attributes taken to inexorably mark groups. Identities are only ever constituted, the author argues, in the relations between groups, where individuals reproduce patterns of similarity and difference through measures of comparison (YOUNG, 2011, p. 171). Nevertheless, this open and fluid nature of identities should not be seen as an impediment to action but precisely as a potential stimulus to public debate, since it affords deliberative contexts that encourage the transformation of opinions and interests (YOUNG, 2000, p. 26) ${ }^{6}$. In her view, the shock of new information,

${ }^{6}$ Some analyses observe differences between Young's works (2011), linked in particular to a valorization of deliberationism in her later works. An examination of these variations, however, 
values and preferences induces the learning of new social experiences and changes to prior opinions based on a lack of knowledge or preconceptions. Additionally, and more importantly, people's interaction with different viewpoints in contexts marked by 'reasonableness', enables a questioning of patterns of domination and oppression, while simultaneously preserving the characteristics of a normative form of dialogical reason (YOUNG, 2011, p. 116).

The concepts of domination and oppression appear at various moments of Young's analyses (2011). Domination is related to institutions that award power to some agents only and hinder the political participation of others, thereby impinging on the self-determination of some groups. Oppression involves limited satisfaction of basic needs and non-recognition of the skills and practices of certain agents and groups, preventing their self-development. An examination of processes of oppression reveals forms of 'cultural imperialism' that cannot be reduced to inequalities created by capitalism. By stereotyping social groups or rendering them invisible, dominant groups project their values and worldviews as universals. These oppressions demand an original approach to justice, therefore, combining the issue of distribution with the fight against modes of normalization, especially those that negatively mark groups via certain categorizations and stereotypes. Justice must vary in response to the demands posed by different groups, which implies rejecting idealizations of unity or the common good that in fact merely reproduce existing power structures and enable the political-cultural skewing of public debates.

The central mechanism used to stimulate self-determination and selfdevelopment without eroding plurality would be a deepening of deliberative democracy. Hence the correct option, Young (2011, pp. 118-119; 2000, p. 109) advocates, is neither a pluralism that institutionalizes the maximizing and selfish attempt to secure scarce assets, nor a republican conception where citizens ideally leave behind their social affinities and ties in search of an ideal of the common good. Rather than following these directions, public space should genuinely include all the groups potentially affected by political decisions. As a consequence, an adequate conception of the public should not presume homogeneity or the need to attain a universal point of view: "to promote a politics of inclusion, then, participatory democrats must promote the ideal of a the author's work and their theoretical-normative implications, see Miguel (2013, pp. 210-220). 
heterogeneous public, in which persons stand forth with their differences acknowledged and respected, though perhaps not completely understood, by others" (YOUNG, 2011, p. 119).

The fundamental point is that the public dimension incorporates the experiences and perspectives of diverse social positionings, which enables a questioning both of the criteria of neutrality and the biases of partial or limited viewpoints. It has become imperative to highlight and valorize the decentred nature of the public sphere and its relations with the State, mediated by agents situated in different localities and spaces. The diversity of the public sphere should be matched by an acceptance of plurality, especially multiple kinds of communication, not always rationally ordered and sometimes indeed emotive and disorganized, expressed through diverse means, including a variety of art forms. Young (2000, p. 170) proposes that groups and associations - themselves the result of a certain organization and formalization - should resituate the particularity of their demands and claims in images and issues accessible to other components of public space, without implying the renouncement of the singularity of its diverse parts. In this sense, fomenting the constitution of a broad and inclusive public sphere - essential to preventing the creation of cultural enclaves or selective separatisms - should be complemented, as Nancy Fraser (2007) notes, by more circumscribed and 'subaltern' public spheres.

In my view, however, two problems arise from this conception of the public domain. First, although the author seeks to address a problem not developed in Kymlicka's analyses, it seems imprecise to examine the relations of groups, associations and public spheres with the state apparatus. Young (2000, p. 156, pp. 184-186) describes these relations when she discusses the limitations of civil society in resolving problems of injustice. According to the author, although civil society has an important role to play in self-determination, its very plurality and lack of coordination leaves it unable to solve the problems of oppression. In these cases, the State has a fundamental role, she argues, since it is the only institution capable of controlling social and economic processes that engender most instances of oppression. However, the State appears in Young's theory (2000) only in the functional role of monitoring the implementation of public policies and resort to coercion when necessary. It is unclear what type of mechanism should be used by the state apparatus, precisely the institution most likely to be approached by groups in order to confront problems of recognition. In addition, 
this turn to the State contradicts various aspects of the author's definition of deliberative democracy, ideally independent of economic and State influences, above all due to the potential of the later to skew public policies, engendering the passivity of agents and the control of civil society associations.

Another problem with Young's theory (2000, p. 113), the most important to emphasize here, concerns her use of the notion of objectivity. In this case, it is unclear how the suppositions of plurality and the consensus potentially resulting from public debates are interconnected. What stands out is the author's attempt to provide normative grounds for deliberativism by appealing to critical and reflexive capacities against critiques of the potential absence of agreements. However, it seems inconsistent to combine the normative suggestion of substantive and generalist social positions with the thesis of debates marked by social diversity and the difficulty of generating consensus.

In similar fashion to the other authors, Bhikhu Parekh (2008) emphasizes how differences challenge the notions of universality present in most modern sociopolitical configurations. There is a common trend among marginalized groups identified as inferior to question the visions of the good life that pervade public debate and that are supposedly legitimized by democratic processes. Hence, for example, women debate gender differences and the values of rationality and emotion; the gay community questions prevailing ideas of nature and sexuality while black people challenge the racialized visions and historical narratives that constitute these societies (PAREKH, 2008, p. 32). Discussing a point also made by Young, Parekh (2008, pp. 62-63) emphasizes that the imposition of a notion of universality and the public sphere is very often nourished by the diffusion of restrictive national identities that project a falsely univocal image. The most problematic consequence of this process is the shaping of society in line with this imaginary and the delimiting of public debate on pseudoontological grounds. Given the inevitability of national States defining communal identities, it is important to foster imaginaries that, even with all their limitations and partialities, regard positively the ethnic, religious and cultural diversity present on their borders ${ }^{7}$.

\footnotetext{
7 Parekh (2008, p. 64) signals that Canada and Australia have moved in this direction, formally declaring themselves multicultural societies, such that diversity becomes the central characteristic of national identification.
} 
The debate advanced by Parekh (2008, pp. 84-86) on integration is exemplified in his critique of the model of universal citizenship. Though recognizing that integration projects - theoretically more sensitive than assimilation projects - seek to incorporate individuals within the framework of rights, duties and opportunities afforded by societies, the author argues that they continue to presume concepts of equality related to similarity and uniformity, failing to conceive the possibility of difference. Parekh (2008) argues that such models display one-way processes of integration in which the costs of social insertion are always met by minorities. While the need is emphasized for the latter to transform their outlooks and values, there is no presumption that society should adapt or alter its normative and legal framework.

At the same time, though, Parekh (2000, p. 219) underlines the idea that multicultural societies require a shared culture. It is the public and private spheres that constitute the foundations of these interactions, and the degree of openness of these spheres reveals the vitality and extent of integration. The State plays an important role in introducing progressive levels of equality between groups, establishing adequate conditions for dialogue that respect diversity. The public sphere, for its part, must not presuppose language standards, forms of discourse, models of participation or unchanging values (PAREKH, 2000, p. 223). In the author's view, rather than generating instability or tensions, acceptance of diversity in the public dimension cultivates a sense of shared belonging to a society that, nonetheless, is able to maintain its differences and accept them in moderated form: "in such a society unity and diversity are not confined to public and private realms respectively, but interpenetrate and permeate all areas of life. Its unity therefore is not formal and abstract but embedded in and nurtured by its diversity" (PAREKH, 2000, p. 224). Such a system allows the emotional depth of all actors to be expressed, irrespective of their group ties, stimulating bonds and processes of common identification in wider society.

Parekh (2008, pp. 87-89), however, is vague concerning the 'moral contract' that defines his notion of public and shared belonging. At the same time that he emphasizes the diversity and differences of contemporary societies, he suggests a type of debate that ultimately constitutes a "common system of rights and obligations" with aspects similar to universal models, supposedly neutral, that he questions. Discussing the role of immigrants vis-à-vis the receiving society, Parekh (2008) argues: "they should value its integrity and well-being, respect its structure of authority and laws, and 
in general discharge their obligations as citizens" (PAREKH, 2008, p. 88, my italics). Despite implying the participation in common life does not entail the abandonment of private cultural spaces, therefore, Parekh (2008) fails to make clear the scope of his conception of the public or define the limits of this association with any precision. The author (PAREKH, 2008, pp. 234-238) seeks to resolve the tension by proposing a mediation between the partiality of special relations and impartial criteria. The latter include, for example, people committing some of their private resources, time, energy and services to others and derive from a moral theory with a strong rationalist meaning, capable of generating rules and general principles (PAREKH, 2008, pp. 236-237). Attempts to resolve these tensions are compromised, however, when Parekh (2008, p. 230) indicates the possibility of the morality of the public debate being based on an impartial equilibrium of positions and claims. Hence, like Young's conception (2000) of objectivity, there remains a certain lack of definition of both the limits of the public domain vis-à-vis the private and the boundaries of political integration in a context of social diversity.

The incorporation of the theme of integration by the theories examined above prompts the need for a more nuanced exploration of the singularities of the multiculturalist framework. On one hand; it is important to note that although multiculturalist approaches never abandon the ideal of promoting and affirming identities, as other interpretations have stressed (CAMPOS and FERES JR., 2014, p. 116), when they incorporate the aim of integration they cannot be taken as a theoretical movement that seeks to valorize identities exclusively. On the other hand, the emphasis on the need for social integration fail to match theses that associate such theories with a simple essentialization or separatism of identities, making it inconsistent, in my view, to conceive of them as an 'identity politics' (FRASER, 2007, p. 106).

Nonetheless, although promoting integration as an aim seeks to address some of the critiques made of multiculturalism over recent years, I think greater emphasis should be given to the fact that, despite their specificities, these tensions demonstrate that its notions of the public and social inclusion remain problematic. Attempts to combine difference and integration can evidently result in somewhat vague normative conceptions and directions, which also tend to problematize and undermine multiculturalism's own critique of political models that depend on an oppressive universalization of concepts and projects. Fundamentally, the theoretical suppositions of 
difference, along with their respective policies based on the affirmation of identities, seem out of synch with formulations of public spaces that incline towards agreement and consensus.

The concepts of difference and integration manifest both the virtues and the flaws of multiculturalist perspectives. As I look to show below, however, there are other analytic and normative issues, linked to these tensions but more generic in nature, that also require our attention when we turn to examine the multiculturalist interconnections between the public realm and its constitutive diversity.

\section{Conclusion}

The main positive point of the theories of Kymlicka, Young and Parekh is (re)thinking the public sphere in terms that do not presume its diminishment under modernity. Turning back to two exemplary theories of public space, namely those of Habermas (1997) and Arendt (2008), we can observe that although both authors signal the potential for interactions in public spheres, what stands out most are themes relating to the impossibility of reason effectively performing its role, in general noting how modern public opinion became manipulated by special interests. Seeking to take into account a public founded on difference, multiculturalist perspectives reveal some rich possibilities for observing and reflecting on new movements and the relations between the private and public domains. In this allows the 'normative core' (BERNSTEIN, 2012) of the public sphere to be reprised with its potential for openness and critique.

This reprisal of the potentialities of the public domain is made possible by a new form of articulation between it and political bodies identified as private. An important factor, then, would appear to be how these authors associate themselves with a much broader set of theories that question traditional oppositions between State and civil society, public and private, such that they incorporate important but previously downplayed symbolic and cultural questions into their analyses of political processes. Rather than reflecting a neutral or impartial set of environments, the public sphere comes to be examined as a realm permeated with problems and demands not previously politicized that concern some of society's basic orientations (see MELUCCI, 1996). The politics of difference, therefore, expresses the possibility of intervention in the symbolic order by questioning sociocultural aspects that reproduce forms of domination and 
oppression irreducible to economic factors and class divisions, though interconnected with them. The theories relate the spheres of politics and culture in a fertile way, advocating concepts that highlight the insertion of individuals in groups and the possibility of reflecting on this involvement. Kymlicka, Young and Parekh jettison fixed and inflexible notions of culture, stressing instead the internal diversity of groups and their inherent transformations. Critiques that identify multiculturalist perspectives with homogenous conceptions of culture would thus seem unfair. For their part, these theories become important in terms of elaborating a new concept of the public sphere in which it makes no sense either to exclude issues taken to be private or unimportant, or to idealize a public subject distinct from real-world actors.

However, despite the originality and productiveness of their approaches, it is crucial to note some shared weaknesses beyond the tensions between difference and integration. Firstly, we need to reflect on the very classification of the authors as adherents of the same theoretical paradigm. It is worth noting the variability of positions relating to the outcomes of the public debate, which range from the emphasis on the capacity of personal choice, as in Kymlicka (1995), to the systemization of an impartial viewpoint defined by Parekh (2008). There are also more specific questions that separate concepts and normative aspects. While Kymlicka (1995) limits his theory to immigrants and national minorities, Young $(2000 ; 2011)$ incorporates various categories in her conception of minority, in part because she attempts to connect her definition of the politics of difference with structural and distributional issues. Kymlicka (2010, p. 57) responds that the issues of foreign workers, black or gipsy populations, for example, are important, but that it would be better to reflect on the successful examples of immigrants. The aspect that most clearly exposes differences in their theories, however, relates to the affiliation of Kymlicka with liberal concepts, not expressed in the same form by Parekh and Young. Parekh (2000), in particular, criticizes this connection where liberal values are taken as the final solution to the problems of minorities and sociocultural conflicts. The author argues that liberalism itself is a cultural artefact, imposed via the hegemony of the West and its model of modernity. Pursuing a different approach, Young's deliberativism (2000) is aimed not at the capacity to revise conceptions of the good life, but at the pluralization of public space and the transformation of social forms of domination and oppression. Such variations reflect different valorizations and tensions within multiculturalist perspectives that, on one 
hand, conceive cultural aspects as assets to be utilized or discarded by agents and, on the other, as a background of practices and institutions that should be value for their own existence and social importance (APPIAH, 2005, pp. 127-130).

Despite these differences, I highlight two general questions shared by the theories examined here that seem to require further clarification. The first concerns the problem of establishing guarantees against forms of oppression when collective rights are granted to groups. Here it is worth citing the argument advanced by Okin (1999, p. 12) who, highlighting the tensions generated by the clash between an universalist policy and measures based on difference, suggests that the multiculturalist perspective pays insufficient attention to the power relations within groups. In the case of a culture based on male domination, for instance, special group rights limit opportunities and status for women. According to Okin (1999), multiculturalism is unable to deal satisfactorily with the fact that the 'private is political' and that the configuration of this private space directly influences the possibilities for participation in a public sphere.

For Okin (1999), it is necessary, then, to critically observe the places that are socially and structurally demarcated within a culture which sometimes hinder its members from achieving personal autonomy. This observation of systematic conditioning factors casts doubt on the optimism in the reflexive capacities of agents enabling them to leave groups when they no longer satisfy them. In turn, it is worth noting the limitations of the differentiation between 'external protections' and 'internal restrictions' as a panacea when it comes to defining the legitimacy of public policies for cultural groups. As well as failing to observe the tethers that frequently constrain individual freedoms and reflexivity, these conceptions, as Appiah (2005, pp. 79-80) observes, are frequently ambiguous since many of the demands made by groups cannot be clearly defined in terms of one single category: what from a strictly personal viewpoint may appear a restriction, may from the viewpoint of groups be a legitimate right against external forms of oppression.

Granting the right to differences, under the pretence that these result from individual choices, may also encourage a kind of non-reflexive and uncritical acceptance of the values and beliefs of social groups. Indeed, there is a chance of reproducing the same problems of unreflected tolerance and relativism of the old paradigm of neutrality supposedly being criticized (SIKKA, 2010). However, many steps are taken to counteract this possibility, suggesting contexts for deliberation or identifying the problem of 
internal restrictions and the heterogeneity of groups, ultimately there should be no impediment to any demand entering public space. The multiculturalist approach may have little to offer in terms of resolving issues such as, for example, a traditional religious group arguing that it is subject to discrimination and unequal treatment since its criticisms of divorce or matters of sexuality are ignored. This does not mean that some common or neutral standard of conflict resolution needs to be found, but that contingent forms of argument and reflection, including their attempts to persuade others, should be present and valued in public debates.

The second question that, I think, requires clearer definition is the normative emphasis given by multiculturalist authors to individual capacities to choose, meaning that their theories, albeit in different ways, are dominated by the premise of a sovereign subject free always to question and even abandon his or her cultural affiliations. When this autonomy in public spaces and in forms of integration is presupposed, frequently insufficient attention is given to processes of domination based on unequal distributions of economic or cultural capital, present even in peripheral public spheres (CALHOUN, 2010). The hypothesis that individuals are situated in some form 'outside' the groups and cultures of which they form part grounds many of the political positions concerning differences. Fundamentally, the diversity of groups is respected because the desire is to preserve individual autonomy: ultimately, it is not groups that possess authenticity; rather, it is individuals who construct their own identities (YOUNG, 2000, pp. 82-83). However, the most important thing to emphasize, I believe, is that this ontological and normative direction, insofar as it reproduces the liberal values of individualism and autonomy, can limit public debate in favour of certain narrow social interests. Though using a multiculturalist theoretical framework, Modood (2003) questions the continuing bias in the selection of demands permitted to enter public debate. A prime example, he suggests, is the question of minority religious practices. Unlike ethnic or racial demands, these are still presumed to be private aspects, excluded from public spheres, even though injustices caused by religious discrimination are strongly present and involve diverse forms of inequality. Because of this focus on the question of individual choices, taken as primary assets by Kymlicka, the relationship between special group rights and other rights remains ill-defined, especially their precedence in relation to other noncommon values and assets, like income, opportunities, and power (CARENS, 1997). 
The emphasis on individual autonomy ends up establishing a dichotomy between the individual and social groups/minorities that effectively replaces the public/private divide. By privileging the sovereignty of the subject and, in parallel, advocating the need to recognize the group differences that individuals themselves deem relevant, the authors seem to lose sight of the fact that agents cannot be fully autonomous and simultaneously be embedded in power networks that subvert some of their freedom. Among many other approaches, this dimension has been explored in theories of discourse and representations (FOUCAULT, 2001; SAID, 1993), for instance. Indeed it is also revealed by the fact that identities are not constituted only through personal preferences but also through sociopolitical processes with multiple causes that define many of the practices and reflexive capacity of agents. Although hegemonic representations can be challenged and transformed, this does not imply that individuals are always conscious of their social insertions and connections to power. These kinds of questions and changes can only be achieved through long-term processes in which many social factors, beyond individual control, become important. Although multiculturalist theories provide original insights into the cultural domination between groups, they seem to suggest, when they reproduced an individual versus groups/cultures dichotomy, an Archimedean point from which subjects can autonomously define their own social reference points and connections. The main danger of such a dichotomy in political terms is the demarcation of a predetermined outcome of the public debate, which turns either to individualism or to the recognition of self-contained groups and identities.

Translated by David Rodgers Submitted on March 14, 2016 Accepted on July 11, 2016

\section{References}

APPIAH, Kwame Anthony (2005), The ethics of identity. Princeton: Princeton University Press. 384pp.

ARENDT, Hannah (2008), A Condição humana. Rio de Janeiro: Forense Universitária. 456pp.

BELL, Daniel (2004) [1993], Communitarianism and its critics. Oxford: Oxford University Press. 272pp. 
BERSTEIN, Richard J. (2012), The normative core of the public sphere. Political Theory. Vol. 40, № 06, pp. 767-778.

CAMPOS, Luiz Augusto e FERES JÚNIOR, João (2014), Ação afirmativa, comunitarismo e multiculturalismo: relações necessárias ou contingentes? Revista Brasileira de Ciências Sociais. Vol. 29, № 84, pp. 103-118.

CALHOUN, Craig (2010), The public sphere in the field of power. Social Science History. Vol. 34, № 03, pp. 301-335.

CARENS, Joseph H. (1997), Liberalism and culture. Constellations. Vol. 04, № 01, pp. 3547.

DWORKIN, Ronald (1985), A Matter of Principle. Cambridge: Harvard University Press. 436pp.

FOUCAULT, Michel (2001), A ordem do discurso. São Paulo: Edições Loyola. 80pp.

FRASER, Nancy (2007), Reconhecimento sem Ética. Lua Nova. Vol. 70, pp. 101-138.

HABERMAS, Jürgen (1997), Direito e democracia. Entre a facticidade e a validade. Vol II. Rio de Janeiro: Tempo Brasileiro. 354pp.

KYMLICKA, Will (1995), Multicultural citizenship. A liberal theory of minority rights. Oxford: Oxford University Press. 296pp.

KYMLICKA, Will (2004), Appendix I: some questions about justice and community. In: Communitarianism and its critics. Edited by BELL, D. Oxford: Oxford University Press. pp. 208-221.

KYMLICKA, Will (2010) [2001], Politics in the vernacular: nationalism, multiculturalism and citizenship. Oxford: Oxford University Press. 391pp.

MELUCCI, Alberto (1996), Challenging codes. Collective action in the information age. Cambridge: Cambridge University Press. 441pp.

MIGUEL, Luis Felipe (2013), Democracia e representação. Territórios em disputa. São Paulo: Editora UNESP. 336pp.

MODOOD, Tariq. (2003), Muslims and the politics of difference. The Political Quarterly. Vol. 74, № 01, pp. 100-115.

OKIN, Susan Moller (1999), Is multiculturalism bad for women? In: Is Multiculturalism Bad for Women? / With Respondents. Edited by COHEN, Joshua; HOWARD, Matthew and NUSSBAUM, Martha C. Princeton: Princeton University Press. 152pp.

PAREKH, Bhikhu (2000), Rethinking multiculturalism: cultural diversity and political theory. Cambridge: Harvard University Press. 367pp. 
PAREKH, Bhikhu (2008), A new politics of identity. Political principles for an interdependent world. Hampshire: Palgrave Macmillan. 328pp.

RAWLS, John (1971), A theory of justice. Cambridge: Harvard University Press. 624pp.

RAWLS, John (2000), O Liberalismo político. São Paulo: Editora Ática. 360pp.

SAID, Edward W. (1993), Culture and imperialism. New York: Vintage Books. 380pp.

SANDEL, Michael J. (1982), Liberalism and the limits of justice. Cambridge: Cambridge University Press. 252pp.

SELIGMAN, Adam B. (1998), Between public and private. Society. Vol. 35, № 03, pp. 2836.

SIKKA, Sonia (2010), Liberalism, multiculturalism, and the case for public religion. Politics and Religion. Vol. 03, № 03, pp. 580-609.

TAYLOR, Charles (2000), Argumentos filosóficos. São Paulo: Edições Loyola. 310pp.

WEINTRAUB, Jeff (1997), The theory and politics of the public/private distinction. In: Public and private in thought and practice: perspectives on a grand dichotomy. Edited by WEINTRAUB, Jeff; KUMAR, Krishan. Chicago/London: The University of Chicago Press. pp. 01-42.

YOUNG, Iris Marion (2000), Inclusion and democracy. Oxford/New York: Oxford University Press. 320pp.

YOUNG, Iris Marion (2011) [1990], Justice and the politics of difference. Princeton/Oxford: Princeton University Press. 304pp. 